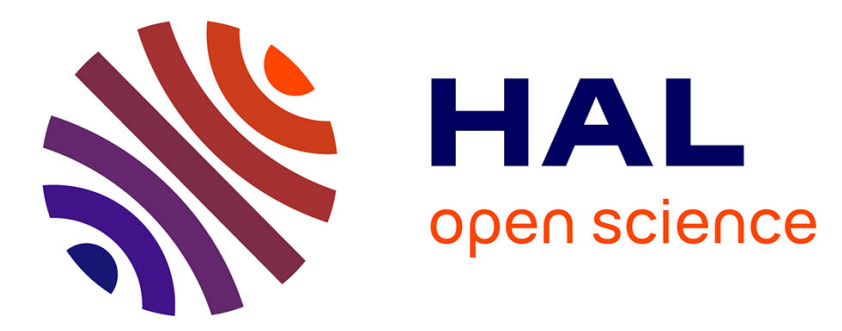

\title{
Generic Business Process Model for SMEs in M-Commerce Based on Talabat's Case Study
}

Fadi Safieddine, Imad Nakhoul

\section{To cite this version:}

Fadi Safieddine, Imad Nakhoul. Generic Business Process Model for SMEs in M-Commerce Based on Talabat's Case Study. 17th Conference on e-Business, e-Services and e-Society (I3E), Oct 2018, Kuwait City, Kuwait. pp.264-278, 10.1007/978-3-030-02131-3_24 . hal-02274190

\section{HAL Id: hal-02274190 \\ https://hal.inria.fr/hal-02274190}

Submitted on 29 Aug 2019

HAL is a multi-disciplinary open access archive for the deposit and dissemination of scientific research documents, whether they are published or not. The documents may come from teaching and research institutions in France or abroad, or from public or private research centers.
L'archive ouverte pluridisciplinaire HAL, est destinée au dépôt et à la diffusion de documents scientifiques de niveau recherche, publiés ou non, émanant des établissements d'enseignement et de recherche français ou étrangers, des laboratoires publics ou privés. 


\title{
Generic Business Process Model for SMEs in M- commerce based on Talabat's Case Study
}

\author{
Fadi Safieddine ${ }^{1}$, Imad Nakhoul ${ }^{2}$ \\ ${ }^{1}$ Queen Mary, University of London \\ School of Business and Management, Mile End Campus \\ , Mile End Road \\ London, E1 4NS, United Kingdom. \\ F.Safieddineeqmul.ac.uk \\ ${ }^{2}$ Nakhoul Corporation sarl \\ Zouk Mikael, Boustany Center \\ 182 Zouk, Lebanon. \\ imad.nakhoul@nakhoulcorp.com
}

\begin{abstract}
SMEs face a variety of challenges in their attempts to keep up with the cyber revolution, even though SMEs are a major part of the world economy. In a previous publication, the authors established that 'B2C' model does not accurately represent or support SMEs in M-Commerce. Instead, the authors reviewed SMEs and SME supporting apps from mobile app marketplaces and suggested a model called 'B2i2C'. In this model, the ' $i$ ', in the form of intermediary business entity are playing a vital role in SMEs breakthrough into M-commerce. Following on, this paper reviews business processes to generate a generic model adaptable to a variety of SME related products and services. This paper presents the case study of Talabat, one of the most successful GCC e-business models that supports SMEs to have come out from Kuwait. The information collected from online resources, student placements and feedback from operation managers attempt to emulate the business process model for a variety of ' $\mathrm{B} 2 \mathrm{i} 2 \mathrm{C}$ ' business models. The generic model is then tested against three different scenarios to identify the level of similarity. The results demonstrate a high degree of adaptability of the model and a major opportunity to explore in the area of SME supporting app in M-Commerce.
\end{abstract}

Keywords: M-commerce, SME, E-commerce, disruptive business model, BPMN, business model, B2i2C.

\section{Introduction}

M-commerce is a method of trading online using wireless mobile devices [1] that has witnessed a revolution in recent years. However, mobile technology has its characteristics, challenges, and restrictions [2]. Businesses interested in having an Internet presence, have several choices. They can have informative websites which provide information related to their products and services with no direct selling or buying involved. Informative websites option remains fairly inexpensive. It is only when a 
business is making that switch to M-commerce that we see a substantial increase in costs and challenges. Despite that, there are significant opportunities that exist in $\mathrm{M}$ commerce for a variety of businesses mainly focused on sales growth. With that, new and disruptive business models [3] continue to outstrip other areas of E-commerce [4]. In moving on towards the M-commerce business model, companies have the option to adapt their existing website to mobiles or to create an app that they can market through one of the key market app stores. Unlike the traditional approach of downloading applications by searching online, mobile application stores provided assurances and trust in the content that resulted in a boom in mobile downloads and M-commerce [5]. The same cannot be said about Web-based M-commerce which has had some limited success [6] as mainly informative. From a consumer point of view, individual Small-to-Medium Enterprise (SME) apps are hard to find, they come with an added cost associated with limited device space, and time spent comparing products/services. Therefore, consumers are reluctant to download individual SME apps for the purpose of comparison or otherwise. So, the real business prospect for SMEs in M-commerce has come from the opportunities to be involved in new business models resulting in some cases in major successes [7]. A new business model involving intermediaries [8,9] as well as Mass Customizations [10]. Together, these two models are considered to have a strong bearing in encouraging SME businesses to adopt an M-commerce initiative. Evidently, there are opportunities for improvements and expansion to new SME related product and services. However, there has been little or no academic documentation to conceptualise the business process model for a successful SMEs supporting app in M-commerce. This paper examines the case study of Talabat, one of the most successful SME supporting apps in the Middle East to develop a generic business process model for B2i2C that can be tested.

\section{$2 \quad$ Literature Review}

SMEs can have several different definitions depending on the region. Most popular definition suggests that an SME is a business that employs 250 or fewer people [11]. In the EU alone, SME represents more than $99 \%$ of businesses [12]. With a study by the World Bank Group suggesting that almost $90 \%$ of SMEs employ less than ten individuals [13]. While many SMEs have developed some online presence, a study in 2017 of the UK and Kuwait app market shows very few independent SMEs have been successful in promoting their mobile apps [9]. This comes from the fact that M-commerce users' needs and expectations vary significantly from E-commerce users resulting in mobile applications being designed differently to E-commerce applications [14]; therefore, presenting real challenges for SMEs. To overcome these challenges, disruptive business models were being experimented to allow SMEs to break into the M-commerce market.

\subsection{M-Commerce models for SMEs:}

A review of the literature shows no specific business models for SMEs or SMEs supporting apps bridging brick-and-mortar operations with a successful M-commerce operation. On the other hand, M-commerce is a derivative of E-commerce, and thus inherits the seven main types of informational added values [15]. However, M-commerce has distinctiveness in what is called the Mobile Added Values (MAV) [16]. MAV helps 
rationalise the challenges we discussed and present a platform for evaluating the adding value and success of M-commerce for SMEs.

\subsection{SMEs and Mass Customisation:}

Before the advent of app marketplace stores, M-commerce had some limited success mainly in areas of informational web pages or sales promotion rather than trading. The real potential of M-commerce was the enabling of individualisation of the application, also called soft customisation, one of the main categories of mass customisation [16]. This specificity allows the apps to adapt to their corresponding devices. It also allowed the user to change the settings of the interface and customise it to their own needs. What is more, the individualisation of the apps allowed better targeting of users with specific content and promotions. On the other hand, Mass Customization goes beyond the experience of the app to the customisation of the product, service, or both. Collectively, SMEs are perfectly fitted to support Mass Customization [17]. According to [18,19], Mass Customization allows clients' involvement in making individual adjustments to products thus producing altered mass quantities that could be offered to the masses.

Some of the first examples of Mass Customization E-commerce business models were service based comparison websites, such as hotel bookings, holiday sales, and insurance services. These E-commerce models went beyond just sales of packages by allowing users to customise packages based on their individual needs. What distinguished them from M-commerce SMEs is that they are not geocentric local SME product or service. Mass Customization of products and services presents a competitive advantage in the lucrative online market [20]. Mass Customization business models allowed the reduction of cost and lead time of Mass Production yet tailor output to meet the individual needs of the customer [21,22]. Technological advancements in Internet communication and M-commerce has facilitated the transition from Mass Production to Mass Customization [21,23] and ushered in a new generation of disruptive business models [24]. Despite this distinctive characteristic, SMEs faced a major hurdle in reaching their local M-commerce audience.

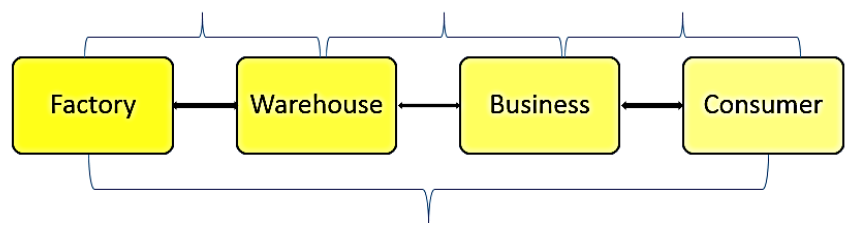

Fig. 1. F2b2C model [27].

\subsection{Disruptive Business models:}

The traditional business models of B2C, B2B, C2B, etc. are facing an onslaught of disruptive business models that are changing the landscape of business operations. In the case of mass customisation, these new models are allowing collaborative development between competing businesses to promote customised products and 
services [25]. An example of such collaborative work is that of the F2b2C model [26]. $\mathrm{F} 2 \mathrm{~b} 2 \mathrm{C}$ involves businesses (b) acting as intermediaries for factories (F) as they send customised products directly to consumers (C) [27] as shown in fig.1. F2b2C represents what some tried to explain as B2B (factory to warehouse), followed by another B2B (intermediary warehouse to business), and finally B2C (business to consumer) [28]. These three models cannot be seen in isolation from each other but rather in an interrelated system since the products are never handled by the intermediary. Instead, these products an services are sent from factory to customer directly [27]. Another model with a specific successful record for SMEs in M-Commerce is B2i2C [9]. In this model, SME are small to medium size businesses (B) who tend to have a niche local exposure at marketing their products or services, (i) are intermediary businesses who provide a platform for comparing products or services with added value, and finally (C) the consumer who is able to compare, customise, and order with assurance of quality and reliability presented by the intermediary source. The role of the intermediary business is specific enough to be given the letter ' $i$ ' as it plays a significant role in developing trust through the independent reviews, the reliability of service, and convenience of not having to overload users' devices with apps or depending to some degree on unreliable online searches. Examples of B2i2C include Uber, an international intermediary taxi service app, Seamless, a US intermediary food delivery app, JustEat, a UK intermediary food delivery app, Trivago, international intermediary hotel booking app, Airbnb, an international private holiday home letting, and Talabat, a Kuwaiti startup that quickly became the GCC most successful food ordering app.

\subsection{Reflection on the literature}

Given the economic impact of SMEs and the ever-evolving landscape of mobile technologies and wearable technologies, understanding SMEs' supporting apps process model is significantly important. The business models presented in the literature do not provide a complete picture or understanding of the actual processes. These models do not explain the business processes involved in SME supporting apps and how they have helped provide new opportunities for SMEs in M-commerce. Understanding the business processes will allow a better overview of how SME collaborations work, the importance of a reliable and trusted intermediary, and opportunities to develop these models in other areas where SMEs have struggled to keep up with the mobile commerce revolution. It is evident that $\mathrm{B} 2 \mathrm{i} 2 \mathrm{C}$ model is being replicated for a variety of products and services and there remain opportunities for new disruptive business models to be developed for the next generation of entrepreneurs.

\section{$3 \quad$ Research Methodology}

To better understand and evaluate the processes involved in $\mathrm{B} 2 \mathrm{i} 2 \mathrm{C}$ and specifically the business processes around SMEs supporting apps, the paper aims to use Business Process Modeling (BPMN) tool followed by a cognitive walkthrough of these processes. There are a variety of business process modeling tools in the market; for example Business Process Model and Notation (BPMN), Business Process Flowchart, UML Use case diagram and Activity Diagram, UML EDOC Business Processes, deployment 
flowchart, IDEF process mapping, Activity-Decision Flow (ADF) Diagram, and EventProcess Chains (EPCs). After the introduction of BPMN in 2004, the model evolved and improved allowing it to achieve standardisation status [29]. According to [30], BPMN has become the most widespread modelling tool to model business processes. Crucial to BPMN success is that the notations are easy to read. Therefore, the model allows easier visualisation of the processes and facilitates discussions among all stakeholders including analysts, developers, and management, while still being able to model intricate processes [31]. According to [32], BPMN success is a testimony to its ability to bridge the gap between business needs for visualising processes and IT needs for representing complex processes. Also, BPMN's many extensions allow a great level of details in areas of security [33], business rules [34], business events [35], and costs analysis [36]. However, it should be noted that in large-scale projects BPMN can be less effective. The model can get complex and difficult to read [37]. We can determine, however, that in the case of modelling the interactions for Talabat, as a generic B2i2C business process, BPMN is a suitable modelling tool to communicate these processes.

To ensure that BPMN is representative of the process, a methodology was devised to collect and cross-reference the information from three sources using a four-step process. First, the team reviewed the information provided online about the process of ordering at Talabat $[38,39]$. In addition, Talabat online sources provided key details regarding how SMEs can join and other processes associated with their ordering system. In the second stage, the team reviewed the Business Process Flowchart (BPF) from a graduate student placement. The model, while not perfect, does connect some of the facts associated with internal processes. In the third step, the BPM is cross-referenced and checked with two of Talabat's operation managers. The Talabat managers contacted via LinkedIn verified existing processes to be valid and identified two missing processes. Finally, given all online sources and the improved BPM, the team developed a generic BPMN for B2i2C, and a cognitive walkthrough [40] is done for three examples of SME's business or services. For this paper, the team selected three unique test cases to perform the cognitive walkthroughs: Taxi ordering service, private holiday apartment rentals, and to stress test the diagram, the team selected a random SME service.

\section{Outcome}

\subsection{Talabat's online sources}

The Talabat website provides some details on how the process of registering SMEs and customers. For SMEs, the join us page explains that the company is the biggest online food ordering service in the GCC, with millions of registered users, and they invest in marketing that benefits the SMEs allowing them to increase their sales. There is also brief information on how the ordering process works [38]:

1. Customers order from Talabat.com using their computers, tablets and smartphones.

2. Customers select their area to find a restaurant that delivers to their area. 
3. Customers order from our graphically rich online menus.

4. Customers pay by card or cash on delivery.

5. The restaurant receives orders on Talabat.com Web Linked Application or other seamless communication terminals.

After that, the SME is encouraged to fill a form to get the process of registering their business started.

For customers, the instructions include creating an account, which they can use social media login if they wish, or order without an account using their mobile number and something called 'express checkout' number. They would then select their geographic area and optionally select the cuisine they prefer and then search. For each restaurant, they can view the menu and add items to the cart. For each item, the customer can customise their order by editing the ingredients or the way it is cooked. Then they can enter their address or use the address that is already saved on the app. The customer can then either pay via the app using their credit or debit card or choose to pay cash on delivery. If it is a new phone number that is making the order, Talabat will ring to confirm it is legitimate [38]. The information on the website also includes a variety of tips on how to use Talabat services and cases where the customer may not be satisfied with the service or product. The website, however, does not explain how the data is handled after the order is collected other than indicating that as soon as the order is placed, the restaurant is instantly informed. This suggests that the communication is done electronically and consistent with the information presented to the SMEs that they will be informed "Web Linked Application or other seamless communication terminals."

\subsection{Generating the Business Process Flowchart:}

Fig. 2 and Fig. 3 represent the BPF process collected from online research and student's placement at Talabat. The model represents an example of an intermediary business entity. To keep the process generic, we will refer to Talabat as the intermediary and the business interested in joining as the SME.

While Fig.2 and Fig3. explains a significant part of the process, these remains based on secondary sources. To verify these details, the team received feedback from two of Talabat's operational managers who indicated that the process is missing the registration, delivery information process, and the routing methods to the vendors. By routing methods, the operation manager indicated that Talabat sends instruction on how to reach customers address. This could be information provided by the customer making the order, by customers who have ordered from that same address, or drivers who have attempted to deliver to that address. This information sharing is very valuable in many countries where addresses are less structured and GPS locations less reliable. Thus, ensuring the delivery arrives on time. 


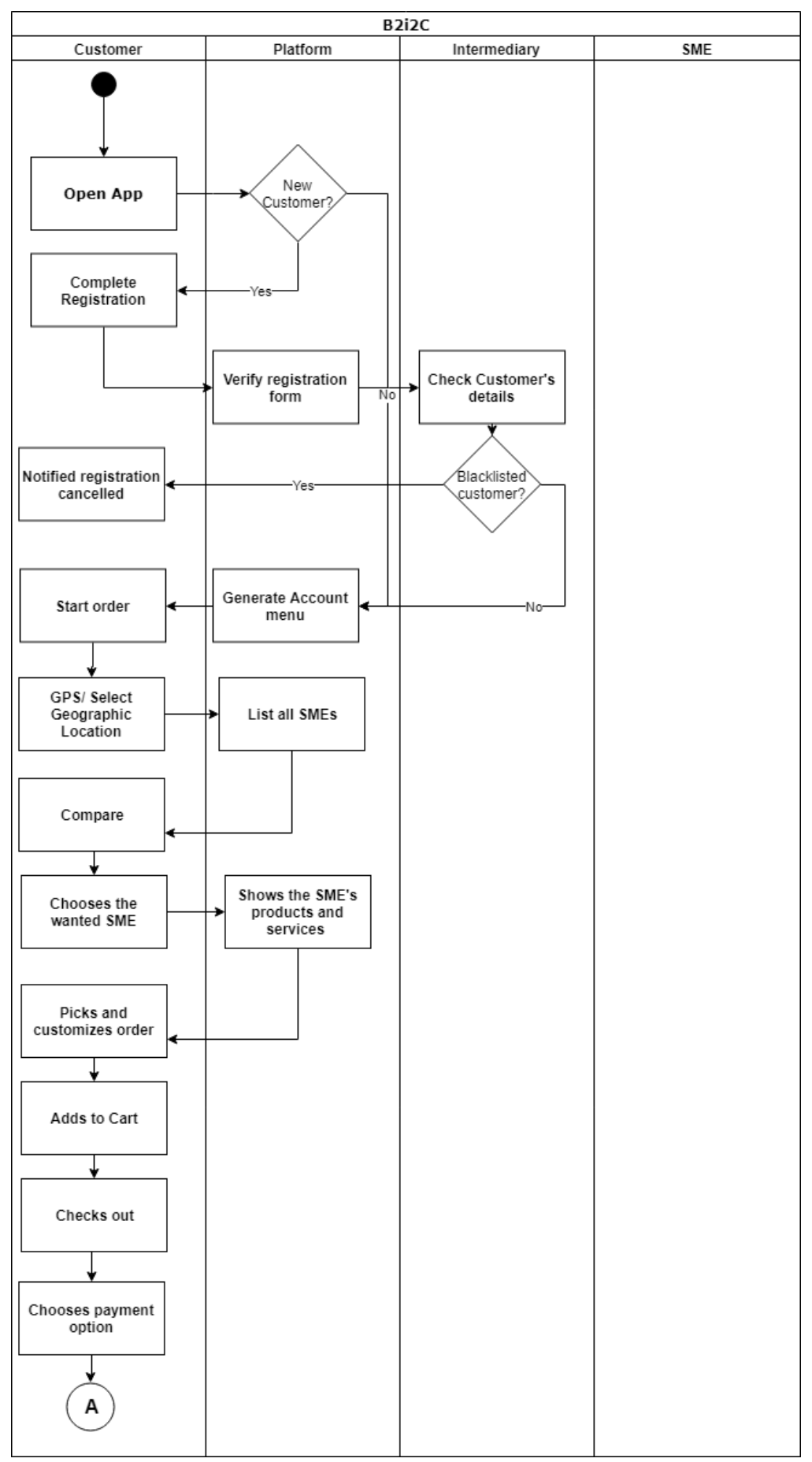

Fig. 2. Phase 1: Business Process Flowchart for Talabat. 


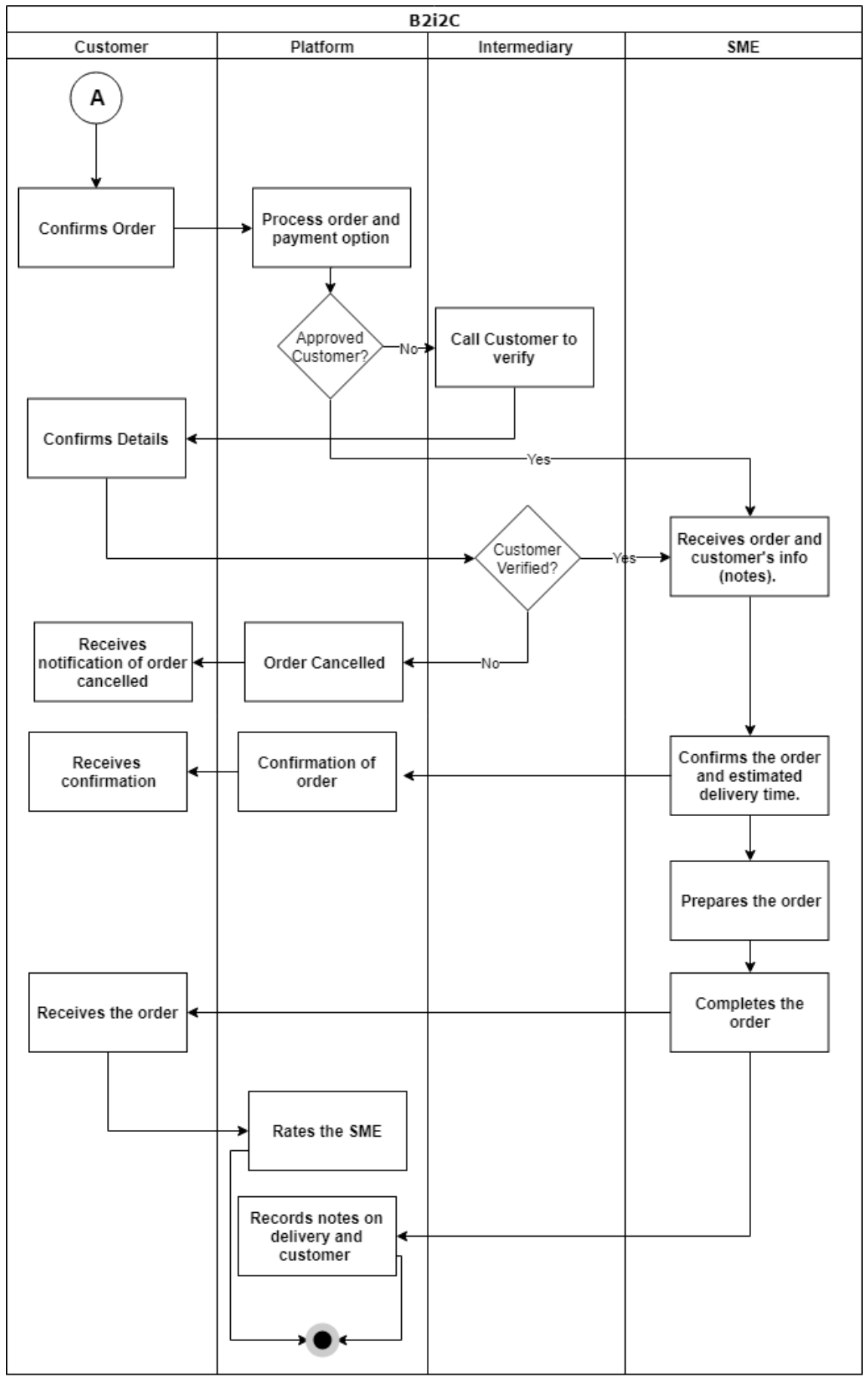

Fig. 3. Phase 2: Business Process Flowchart for Talabat. 


\subsection{Generic BPMN for B2i2C:}

Using Fig. 2 and Fig. 3 the team constructed a generic BPMN model for order taking for SME participation in M-Commerce model for B2i2C as presented in Fig.4 with a breakdown in fig. 5, 6, 7, and 8 .

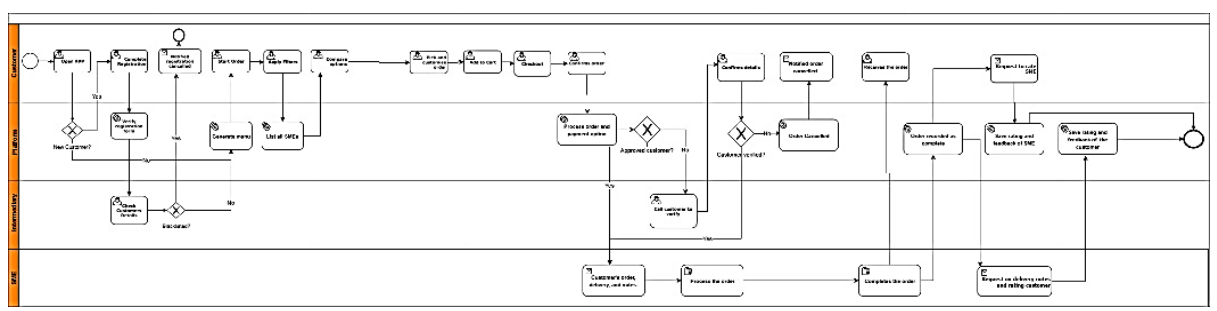

Fig. 4. Overview of the model.

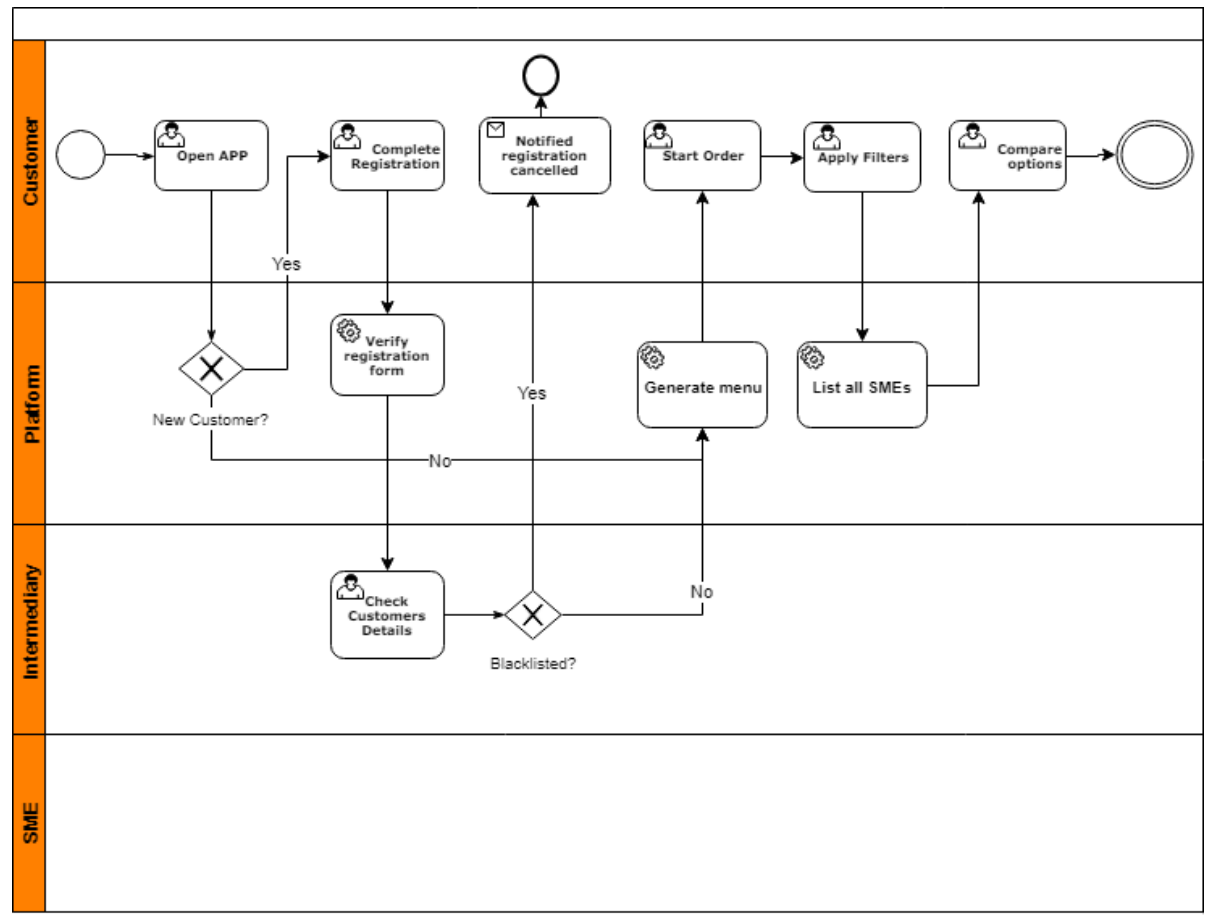

Fig. 5. Generic BPMN Phase 1: Registration and start of the order process. 


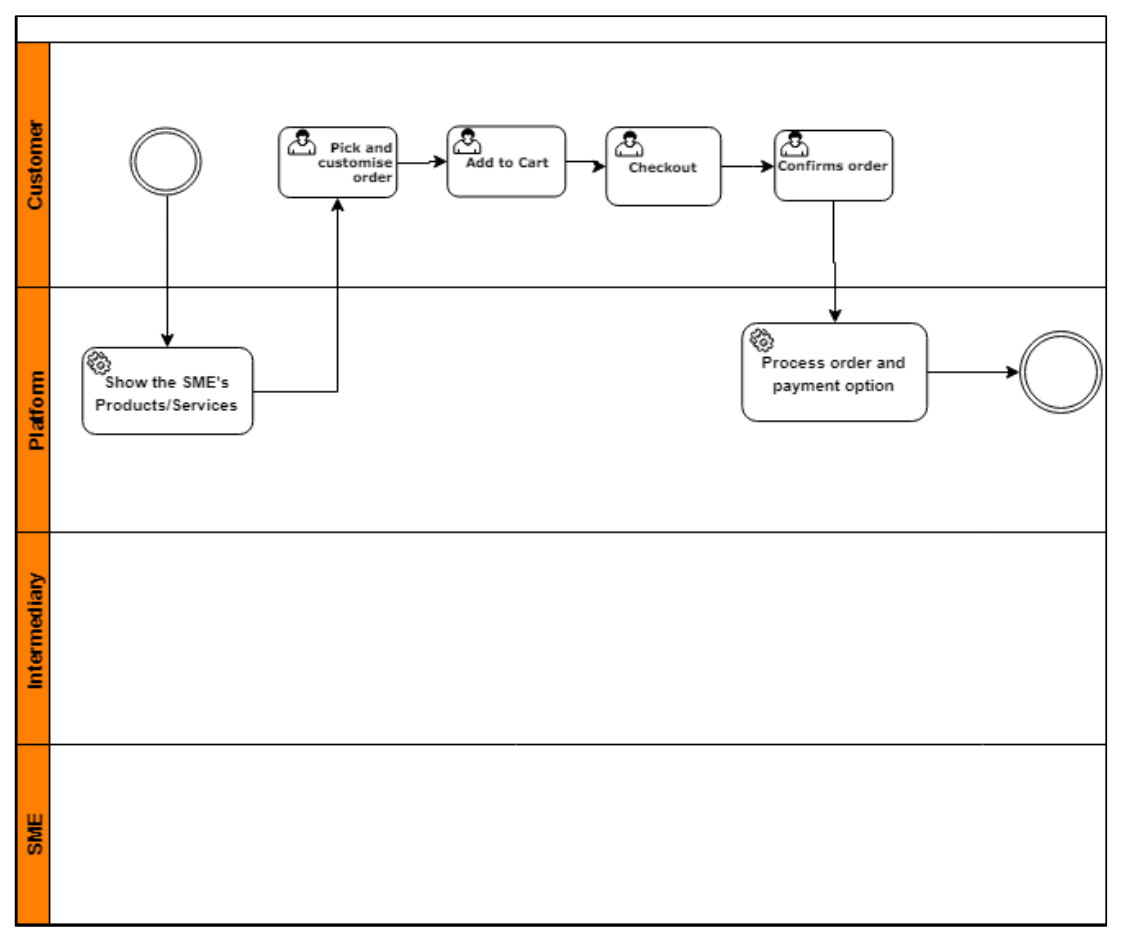

Fig. 6. Generic BPMN Phase 2: Order Process.

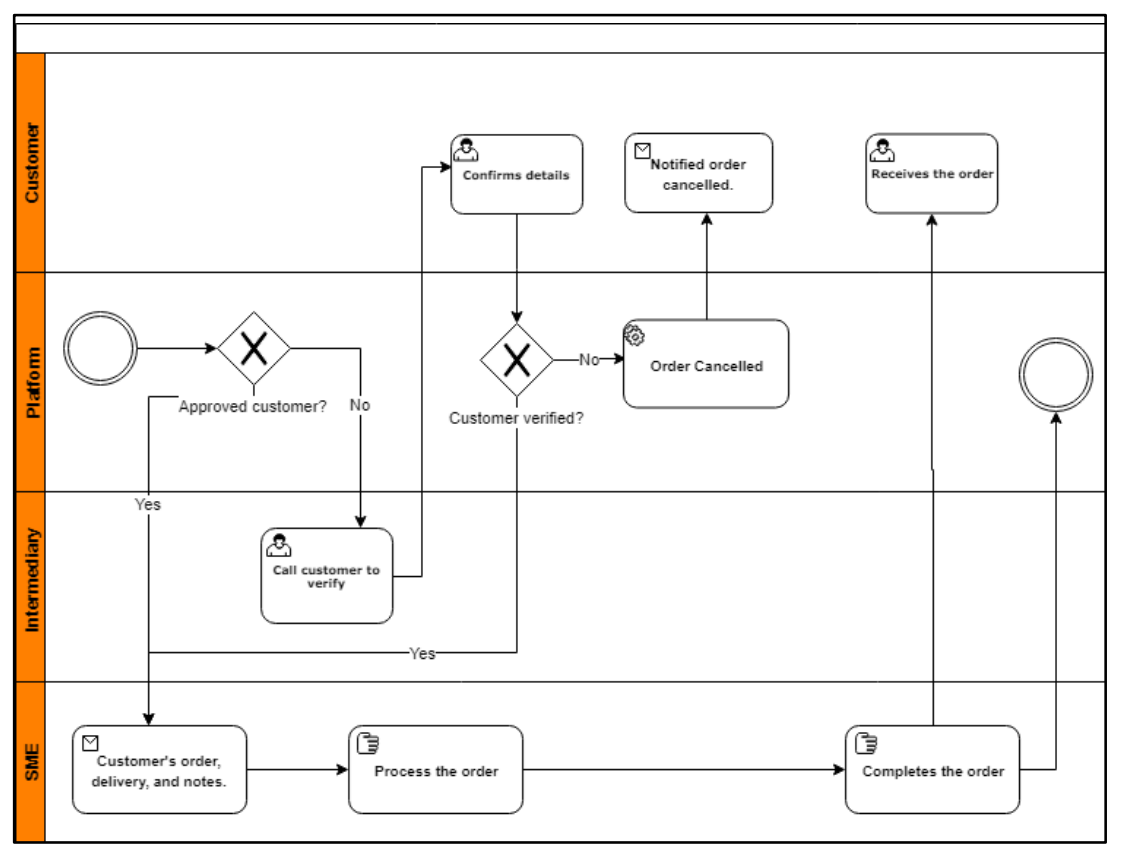

Fig. 7. Generic BPMN Phase 3: Delivery of order. 


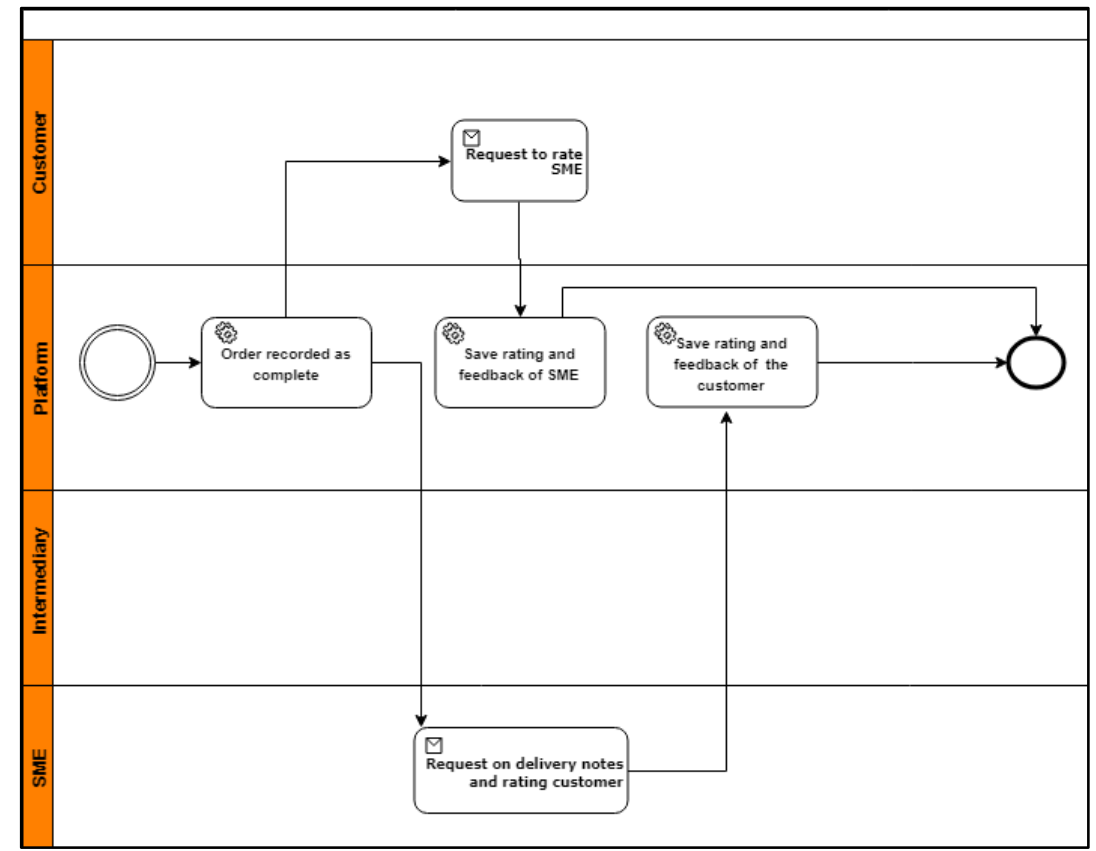

Fig. 8. Generic BPMN Phase 4: Completing order and feedback.

To test the model for its flexibility and generic applications in another context, the team ran cognitive walkthroughs for taxi ordering service, private holiday apartment rentals, and to truly test the diagram a random SME service in the form of laundry shops in table 1.

\begin{tabular}{|c|c|c|c|c|}
\hline Role & Process & $\begin{array}{l}\text { Case 1: } \\
\text { Taxi }\end{array}$ & $\begin{array}{c}\text { Case 2: } \\
\text { Aprt }\end{array}$ & $\begin{array}{l}\text { Case 3: } \\
\text { Laundry }\end{array}$ \\
\hline Customer & Open App & $\checkmark$ & $\checkmark$ & $\checkmark$ \\
\hline Platform & New customers? & $\checkmark$ & $\checkmark$ & $\checkmark$ \\
\hline Customer & Complete Registation & $\checkmark$ & $\checkmark$ & $\checkmark$ \\
\hline Platform & Verify registration form & $\checkmark$ & $\checkmark$ & $\checkmark$ \\
\hline Intermediary & Check Customers Details & $\checkmark$ & $\checkmark$ & $\checkmark$ \\
\hline Intermediary & $\begin{array}{l}\text { Check if the customer is } \\
\text { blacklisted? }\end{array}$ & $\checkmark$ & $\checkmark$ & $\checkmark$ \\
\hline Customer & 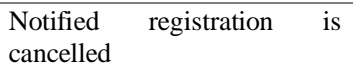 & $\checkmark$ & $\checkmark$ & $\checkmark$ \\
\hline Platform & Generate Menu & $\checkmark$ & $\checkmark$ & $\checkmark$ \\
\hline Customer & Start Order & $\checkmark$ & $\checkmark$ & $\checkmark$ \\
\hline Customer & Apply Filter & $\checkmark$ & $\checkmark$ & $\checkmark$ \\
\hline Platform & List all SMEs & $\checkmark$ & $\checkmark$ & $\checkmark$ \\
\hline Customer & Compare options & $x$ & $\checkmark$ & $\checkmark$ \\
\hline Customer & Choose SME & $x$ & $\checkmark$ & $\checkmark$ \\
\hline Platform & $\begin{array}{l}\text { Show the SME's prod- } \\
\text { ucts/Services }\end{array}$ & & $\checkmark$ & $\checkmark$ \\
\hline
\end{tabular}




\begin{tabular}{|c|c|c|c|c|}
\hline Customer & Pick and customise the order & $\checkmark$ & $\checkmark$ & $\checkmark$ \\
\hline Customer & Add to cart & $\checkmark$ & $\checkmark$ & $\checkmark$ \\
\hline Customer & Checkout & $\checkmark$ & $\checkmark$ & $\checkmark$ \\
\hline Customer & Confirms order & $\checkmark$ & $\checkmark$ & $\checkmark$ \\
\hline Platform & $\begin{array}{l}\text { Process order and payment } \\
\text { option }\end{array}$ & $x$ & $\checkmark$ & $\checkmark$ \\
\hline Platform & Is customer approved? & $\checkmark$ & $\checkmark$ & $\checkmark$ \\
\hline Intermediary & Call customer to verify & $\checkmark$ & $\checkmark$ & $\checkmark$ \\
\hline Customer & Confirms details & $\checkmark$ & $\checkmark$ & $\checkmark$ \\
\hline Platform & Customer verified? & $\checkmark$ & $\checkmark$ & $\checkmark$ \\
\hline Platform & Order Cancelled & $\checkmark$ & $\checkmark$ & $\checkmark$ \\
\hline Customer & Notified Order cancelled & $\checkmark$ & $\checkmark$ & $\checkmark$ \\
\hline SME & $\begin{array}{l}\text { Receives order, delivery, and } \\
\text { notes }\end{array}$ & $\checkmark$ & $\checkmark$ & $\checkmark$ \\
\hline SME & Process the order & $\checkmark$ & $\checkmark$ & $\checkmark$ \\
\hline SME & Complete the order & $\checkmark$ & $\checkmark$ & $\checkmark$ \\
\hline Customer & Receives the order & $\checkmark$ & $\checkmark$ & $\checkmark$ \\
\hline Platform & Order recorded as complete & $\checkmark$ & $\checkmark$ & $\checkmark$ \\
\hline Customer & Receives request to rate SME & $\checkmark$ & $\checkmark$ & $\checkmark$ \\
\hline Platform & $\begin{array}{l}\text { Save rating and feedback of } \\
\text { SME }\end{array}$ & $\checkmark$ & $\checkmark$ & $\checkmark$ \\
\hline SME & $\begin{array}{l}\text { Receives request for delivery } \\
\text { notes and rating customer }\end{array}$ & $\checkmark$ & $\checkmark$ & $\checkmark$ \\
\hline Platform & $\begin{array}{l}\text { Saves rating and feedback of } \\
\text { the customer }\end{array}$ & $\checkmark$ & $\checkmark$ & $\checkmark$ \\
\hline
\end{tabular}

Table 1 demonstrates that in all three scenarios, the generic model closely matched the expected processes. Where there are discrepancies, in three processes associated with taxi ordering, the processes of comparing SMEs and choosing SME is done by the platform rather than the customer. The third process, processing payment, happens after the service is completed and not before delivery. This walkthrough proved that the model is sufficiently generic and where differences are to be applied, these are minor and are associated with handling or sequence.

\section{Conclusion}

The paper set out to develop and prove a generic BPMN model for SME supporting apps based on a successful business model known as Talabat. The team were successful in demonstrating the applicability of the model in at least three case studies. Thus, this paper has helped formulate a model that could be adapted to new and emerging B2i2C models. The team acknowledges research limitation in the fact the model is based on only one case study and one type of product and service. The team also acknowledges that the three case studies used in the applicability test are conducted as a walkthrough rather than a field investigation. Further research is recommended to identify areas of improvements, missed details and exceptions. The model could also be expanded to explore new applications in areas not exploited thus opening new opportunities for SMEs in competing in an ever-changing digital market. In addition, ethical considerations need to be explored including regulations to ensure processes monopolised by major intermediaries are fair and allow ethical practices in how they support SMEs and consumers. Failure to do so will be detrimental to competition, diversity of SMEs, and consumers. 
At the time of writing this paper, competition between intermediaries was found to be limited.

\section{References}

1. Veijalainen $\mathrm{J}$, Terziyan $\mathrm{V}$, Tirri $\mathrm{H}$. Transaction management for $\mathrm{m}$-commerce at a mobile terminal. Electronic Commerce Research and Applications. 2006 Sep 1;5(3):229-45.

2. Felt AP, Finifter M, Chin E, Hanna S, Wagner D. A survey of mobile malware in the wild. In: Proceedings of the 1st ACM workshop on Security and privacy in smartphones and mobile devices 2011 Oct 17 (pp. 3-14). ACM.

3. Johnson MW, Christensen CM, Kagermann H. Reinventing your business model. Harvard business review. 2008 Dec 1;86(12):57-68.

4. Wakabayashi D. Apple's App Store Sales Hit \$20 Billion, Signs of Slower Growth Emerge. The Wall Street Journal, last accessed 11th of March. 2018.

5. Sanz B, Santos I, Laorden C, Ugarte-Pedrero X, Bringas PG, Álvarez G. Puma: Permission usage to detect malware in android. InInternational Joint Conference CISIS'12-ICEUTE 12-SOCO 12 Special Sessions 2013 (pp. 289-298). Springer, Berlin, Heidelberg.

6. The state of Mobile Applications for Retailers. Forrester Consulting. August 2015.

7. Safieddine, F. M-commerce. In S. Kadry, and A. El-Hami (Ed.), Innovations in E-Systems for Business and Commerce. London, UK. CRC Routledge Publishing. 2016.

8. Anderson P, Anderson E. The new e-commerce intermediaries. MIT Sloan Management Review. 2002 Jul 1;43(4):53.

9. Nakhoul I, Safieddine F, Ismail R. Introducing B2i2C: An M-commerce model for SMEs. In: IEEE Engineering \& MIS (ICEMIS), 2017 International Conference on 2017 May 8 (pp. 1-5). IEEE.

10. Kaplan AM, Haenlein M. Toward a parsimonious definition of traditional and electronic mass customization. Journal of product innovation management. 2006 Mar 1;23(2):168-82.

11. Hauser M. A qualitative definition of SME. In: SBS Expert Meeting-Towards better Structural Business and SME statistics, OECD, Paris 2005 Nov.

12. Verheugen G. The new sme definition: user guide and model declaration. Enterprise and Industry Publications, European Commission. 2005.

13. Kushnir K, Mirmulstein ML, Ramalho R. Micro, small, and medium enterprises around the world: how many are there, and what affects the count. Washington: World Bank/IFC MSME Country Indicators Analysis Note. 2010:1-9.

14. Gonzalez JD. A roadmap to wireless: The state of the technology. Atlanta, GA: Air2Web, Inc. 2002.

15. Bazijanec B, Pousttchi K, Turowski K. An approach for assessment of electronic offers. In: International Conference on Formal Techniques for Networked and Distributed Systems 2004 Sep 27 (pp. 4457). Springer, Berlin, Heidelberg.

16. Pousttchi K, Selk B, Turowski K. Enabling mobile commerce through mass customization. In: Workshop on Information Systems for Mass Customization 2002 (pp. 1-6).

17. Svensson C, Barfod A. Limits and opportunities in mass customization for "build to order" SMEs. Computers in industry. 2002 Sep 1;49(1):77-89.

18. Pine, B. Joseph. Mass customization: the new frontier in business competition. Harvard Business Press, 1993.

19. Tseng MM, Hu SJ. Mass customization. InCIRP Encyclopedia of Production Engineering 2014 (pp. 836-843). Springer Berlin Heidelberg.

20. Piller F, Reichwald R, Möslein K. Mass customization based e-business strategies. In: Proceedings of the SMS 20th International Conference 2000 Oct 15.

21. Helms MM, Ahmadi M, Jih WJ, Ettkin LP. Technologies in support of mass customization strategy: Exploring the linkages between e-commerce and knowledge management. Computers in Industry. 2008 Apr 1;59(4):351-63.

22. Piller FT, Moeslein K, Stotko CM. Does mass customization pay? An economic approach to evaluate customer integration. Production planning \& control. 2004 Jun 1;15(4):435-44.

23. Kamali N, Loker S. Mass customization: On-line consumer involvement in product design. Journal of Computer-Mediated Communication. 2002 Jul 1;7(4):JCMC741.

24. Wind J, Rangaswamy A. Customerization: The next revolution in mass customization. Journal of interactive marketing. 2001 Jan 1;15(1):13-32. 
25. Helander M, Zhang L. Web-based configure-to-order platform for collaborative development of customized products. InCyberworlds, 2005. International Conference on 2005 Nov 23 (pp. 8-pp). IEEE.

26. Lu, S.C. F2B2C - the Last Ten Miles of a Complete E-commerce Model, a keynote speech at 2001 Cybermediaries Conference, San Francisco, CA.

27. Haag S, Cummings M, Dawkins J. Management information systems. Multimedia systems. 2013, pp. 280-97.

28. Tseng MM, Kjellberg T, Lu SC. Design in the new e-commerce era. CIRP Annals-Manufacturing Technology. 2003 Jan 1;52(2):509-19.

29. White SA. BPMN modeling and reference guide: understanding and using BPMN. Future Strategies Inc.; 2008.

30. Aagesen G, Krogstie J. Analysis and design of business processes using BPMN. In: Handbook on Business Process Management 12010 (pp. 213-235). Springer, Berlin, Heidelberg.

31. Birkmeier D, Overhage S. Is BPMN really first choice in joint architecture development? an empirical study on the usability of BPMN and UML activity diagrams for business users. In: International Conference on the Quality of Software Architectures 2010 Jun 23 (pp. 119-134). Springer, Berlin, Heidelberg.

32. Rodríguez A, Fernández-Medina E, Piattini M. A BPMN extension for the modeling of security requirements in business processes. IEICE transactions on information and systems. $2007 \mathrm{Apr}$ 1;90(4):745-52.

33. Milanovic M, Gaševic D, Wagner G. Combining rules and activities for modeling service-based business processes. In: Enterprise Distributed Object Computing Conference Workshops, 2008 12th 2008 Sep 16 (pp. 11-22). IEEE.

34. M. Milanovic, D. Gaševic, and G. Wagner, "Combining rules and activities for modeling service-based business processes," in Enterprise Distributed Object Computing Conference Workshops, pp.11-22, IEEE, September 2008.

35. Decker G, Grosskopf A, Barros A. A graphical notation for modeling complex events in business processes. In: Enterprise Distributed Object Computing Conference, 2007. EDOC 2007. 11th IEEE International 2007 Oct 15 (pp. 27-27). IEEE.

36. Magnani M, Montesi D. BPMN: How much does it cost? An incremental approach. In: International Conference on Business Process Management 2007 Sep 24 (pp. 80-87). Springer, Berlin, Heidelberg.

37. Zur Muehlen M, Recker J, Indulska M. Sometimes less is more: Are process modeling languages overly complex?. In: EDOC Conference Workshop, 2007. EDOC'07. Eleventh International IEEE 2007 Oct 15 (pp. 197-204). IEEE.

38. Talabat Frequently Asked Questions Page, https://www.talabat.com/uae/faq, last accessed 2018/04/21

39. Talabat Contact Us Page (join us tab), https://www.talabat.com/uae/contact-us, last accessed 2018/04/21.

40. Blackmon MH, Polson PG, Kitajima M, Lewis C. Cognitive walkthrough for the web. In: Proceedings of the SIGCHI conference on human factors in computing systems 2002 Apr 20 (pp. 463-470). ACM. 